\title{
CURIOSIDADE, COMPROMISSO E SERIEDADE - PEQUENA HOMENAGEM AO PROF. DR. SERGIO ANTONIO CARLOS
}

No dia 29 de julho de 2021, perdemos o Professor Sergio, perdemos um colega querido, um grande estudioso do envelhecimento, um professor e pesquisador dedicado. Para nós, na UFRGS, no Núcleo, na Revista, o Sergio fará muita falta. Deixou-nos, de certa forma, órfãos pois com sua experiência, seus conhecimentos, sua generosidade e sua seriedade, sempre foi uma referência em situações complicadas e desafiadoras. Nesta pequena homenagem que a revista "Estudos Interdisciplinares sobre o Envelhecimento" presta ao seu fundador e Editor Chefe por mais que 15 anos, queremos mostrar algumas das facetas que tornaram o Sergio tão importante para muitas pessoas, alunos, colegas e amigos.

Para lembrar e homenagear em memória do Sergio, unimos aqui quatro pequenos textos que o relembram, cada um na sua perspectiva particular. Temos uma homenagem dos colegas da graduação em Serviço Social e da pós-graduação em Política Social e Serviço Social UFRGS, as recordações da biblioteca do Instituto de Psicologia, os comentários de um colega do grupo editorial da revista e a voz de um ex-aluno. 
A trajetória do Prof. Sérgio deixou marcas em muitas gerações! Sua contribuição para além da atividade profissional e acadêmica, está na sua presença significativa na vida de todos que conviveram com ele e que foram pelo mesmo sensivelmente tocados.

Nosso amigo e colega, Prof. Sérgio, Assistente Social, Doutor em Serviço Social (PUCSP) foi professor na PUCRS e ingressou como docente efetivo da UFRGS em 1977, no Instituto de Psicologia, no qual também foi Vice-Diretor por dois períodos (1998-2000 e 2002-2006).

Evidenciou seu compromisso ético e político por meio de uma trajetória marcada por participação em espaços coletivos e representação de sua categoria, como na ocasião em que assumiu a presidência do Conselho Regional de Serviço Social - CRESSRS (1993-1996). Destaca-se a referência do Sérgio na área de envelhecimento, na qual além de pesquisar e produzir, também contribuiu nas instâncias de controle social, por meio de seu envolvimento nos conselhos de direito, participando como conselheiro do Conselho Estadual do Idoso do Rio Grande do Sul (1998-2002) e do Conselho Nacional dos Direitos da Pessoa Idosa (2018-2020). Na universidade, foi Coordenador do Núcleo de Estudos Interdisciplinares sobre o Envelhecimento (1994-1999) e editor da Revista Estudos Interdisciplinares sobre o Envelhecimento desde 1999, esta que é a maior referência na área de envelhecimento no RS. Nosso colega, deixou seu legado também nas disciplinas específicas que lecionou na graduação e na pós-graduação sobre envelhecimento, tema que buscou sempre garantir na pauta dos currículos, contribuindo assim para qualificação da formação em nível de graduação e pós-graduação.

Sua implicação e compromisso também são evidenciados por meio da contribuição na construção do primeiro Projeto Político Pedagógico e na criação do Curso de Serviço Social da UFRGS, em 2009; além de ter sido o primeiro membro do Serviço Social na CoorSaúde. Em 2010 foi o primeiro coordenador da Comgrad de Serviço Social; em 2013 o primeiro chefe do Departamento de Serviço Social e em 2016 esteve na criação do PPG de Política Social e Serviço Social, no qual era professor colaborador até esse momento.

Nosso mestre e referência deixou um legado ao Serviço Social. Prestamos reconhecimento e gratidão pela construção do curso de seu marco na história do Serviço Social no Rio Grande do Sul.

Seu cuidado e rigor estava presente em todas as atividades, no exercício e ensino da pesquisa, no planejamento das aulas, no uso das tecnologias digitais, nas informações sobre o funcionamento da UFRGS, nas suas partilhas de vida e ensinamentos. Também sempre tinha um tempo para nos convidar para tomar um café ou oferecer algo para nos alimentar de forma saudável! 
Sua inquietude com o conhecimento estava sempre à frente, como bem registrou na nota da Biblioteca do Instituto de Psicologia

Prof. Sergio contava as histórias de um pesquisador que tinha que vasculhar os catálogos impressos de teses e dissertações, muitas vezes ir até as bibliotecas das universidades de lugares distantes (...) a pesquisa bibliográfica era para ele uma aventura, e assim ele percorria incansavelmente a produção brasileira sobre envelhecimento, seu grande tema de pesquisa. ${ }^{1}$

Seu legado de generosidade, afeto, acolhida e cuidado estão guardados na memória e coração de seus estudantes, orientandos, colegas, amigos e todos que com ele conviveram.

Na ocasião de seu discurso de formatura do Curso de Serviço Social, como paraninfo em 2017, nosso amigo e colega escolheu uma canção de referência, que agora com sua passagem, nos inspira a seguir, "tocando em frente" e honrando sua memória.

Todo mundo ama um dia

Todo mundo chora

Um dia a gente chega

E no outro vai embora

Cada um de nós compõe a sua história

Cada ser em si

Carrega o dom de ser capaz

E ser feliz.

Almir Sater, Tocando em Frente.

Com saudade, teus colegas da graduação em Serviço Social e da pós-graduação em Política Social e Serviço Social UFRGS.

Nas tardes em que o Professor Sérgio passava pela Biblioteca, sabia que teríamos boas conversas.

Era um amigo que chegava ávido para compartilhar o brilho no olho que surgia sempre que os assuntos eram livros, pesquisa bibliográfica, história das bases de teses e dissertações.

1 Nota de pesar publicada na página da Biblioteca do Instituto de Psicologia da UFRGS no Facebook. Disponível em: https://www.facebook.com/BibPsico.UFRGS/posts/4323095924408707. 
Entre comentários sobre os caminhos da ciência aberta, repositórios e bases digitais, o professor contava histórias de um pesquisador que tinha que vasculhar os catálogos impressos de teses e dissertações e muitas vezes ir até as bibliotecas das universidades. Aproveitava, e muito, viagens a congressos para fazer estas buscas nas bibliotecas de lugares distantes.

Assim, contava-nos, a pesquisa bibliográfica era para ele uma aventura, e por meio dela percorria, incansavelmente, a produção brasileira sobre envelhecimento, seu grande tema de pesquisa, no qual é imensa referência.

Nas nossas conversas, Sérgio era o contraste entre seus cabelos e bigode brancos e um espírito de criança, de um menino que se encantava e nos fascinava com um jogo ou brinquedo novo, e que queria contar ao mundo sobre ele. Mesmo com seus mais de 40 anos como docente, Sérgio se encantava.

Reverenciava profundamente as bibliotecas e a profissão dos bibliotecários. Tinha-nos como grandes parceiros em sua grande aventura. Reconhecia, na difícil tarefa de encontrar os trabalhos sobre seu tema, fosse nos fichários datilografados das bibliotecas de outrora, fosse nas buscas avançadas com operadores booleanos nos repositórios e sistemas de descoberta de hoje, o trabalho dos bibliotecários na organização e disseminação da informação.

Com profundo pesar soubemos que ontem, 29 de julho de 2021, o Professor Sérgio Antônio Carlos faleceu. Escrevemos em uma fria tarde de inverno, pensando com tristeza que não receberemos mais as alegres visitas do Prof. Sérgio, contando suas novas descobertas, escutando nossas dicas de pesquisa, sempre ensinando e aprendendo nas tardes da Biblioteca.

Deixa a nós um legado imensurável, nas suas pesquisas e orientações, mas, principalmente, em todos os olhos que brilham para a aventura do conhecimento, inspirados pelos seus.

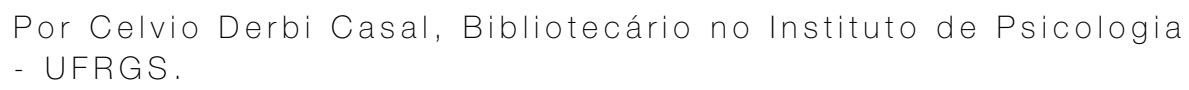

Sergio - generoso, paciente e na luta contra o superficial

Foi no início de 1999. O Núcleo de Estudos Interdisciplinares sobre o Envelhecimento da UFRGS, um grupo de professores e técnico-administrativos envolvidos com questões do envelhecimento sob coordenação do Prof. Sergio Antonio Carlos, decidiu que seria na hora de lançar uma revista sobre o envelhecimento.

Naquela época, o envelhecimento ainda era um tema de poucos estudiosos e se escutava muito que nesta área não tinha literatura e referências. Este discurso de falta de literatura, geralmente causada por preguiça de realizar 
uma busca mais atenta nas bibliotecas, incomodava o Sergio, pois nas suas pesquisas ele tinha encontrado material interessante. Como o Sergio ainda tinha uma verba de um projeto de pesquisa para publicação, ele resolveu investir este dinheiro na ideia do Núcleo dando início à revista "Estudos Interdisciplinares sobre o Envelhecimento", que foi lançada em maio de 1999. Acredito que o seguinte trecho, retirado do editorial do primeiro número da revista, escrito pelo próprio Sergio, mostra suas preocupações principais: divulgação de informações corretas e embasadas, promoção de um espaço aberto para contribuições de qualidade, seja de pesquisadores internacionais, seja de alunos da iniciação científica, e tudo isso para contribuir com políticas públicas à pessoa idosa.

\section{Entre os objetivos do Núcleo está também a divulgação e discussão da temática do envelhecimento enquanto importante espaço no desmonte de mitos e na formulação de subsídios para Políticas Públicas na área do idoso. É com este objetivo que se estabeleceu este Caderno, apresentando artigos sobre temas de interesse geral. Inclui desde textos de autores com grande circulação nacional e internacional até de iniciantes bolsistas vinculados ao Núcleo. ${ }^{2}$}

Este primeiro número, que já incluiu um artigo internacional, deu início a uma das mais importantes revistas sobre envelhecimento no Brasil. Foi o resultado de um longo e árduo trabalho, que só foi possível pela dedicação e insistência do Sergio. Este caminho começou com os "cadernos vermelhos" que foram oferecidos e vendidos em congressos e eventos sobre o envelhecimento com o intuito de conseguir o dinheiro para a próxima publicação. Passou pela fase de conseguir contribuições de pesquisadores para uma revista que ainda era desconhecida, e pela busca por avaliadores competentes para garantir um processo de avaliação dupla cega com qualidade.

Aos poucos, surgiram apoios principalmente da UFRGS através do edital de periódicos e da Pró-Reitoria de Extensão através da ajuda para as correspondências e do fornecimento de material de escritório. O processo ainda era muito manual, o recebimento de artigos e o encaminhamento para as avaliações eram feitos via correio. $\mathrm{O}$ avanço da digitalização tornou esse processo mais fácil e rápido, e Sergio tinha fascínio em descobrir as potencialidades desse novo recurso.

Os próximos passos foram a digitalização da revista, durante um tempo em paralelo com a versão impressa, a digitalização das versões antigas da

2 CARLOS, Sergio Antonio. Editorial. Estudos Interdisciplinares sobre o Envelhecimento, Porto Alegre, v. 1, 1999. 
revista e os processos de indexação. Quando o Sergio passou a função de editor chefe adiante, depois de mais de 15 anos de dedicação, ele entregou uma revista reconhecida e respeitada nacionalmente. Apesar de ter passado a função de editor chefe, Sergio continuou ativo no trabalho da equipe editorial, assumindo a função da triagem inicial. A função mais importante, porém, foi a de ser o conselheiro capaz de, a partir da sua longa experiência e competência, orientar e ajudar a equipe editorial nos problemas e desafios que aparecem no trabalho de editar uma revista científica.

Do rico trabalho do Sergio escolhi a dedicação à revista. Afinal, foram muitos anos, muito trabalho, muita dedicação que ele dirigiu a essa obra. A forma como o Sergio se envolveu na revista mostra bem várias características que o tornaram tão especial. Por um lado, uma generosidade com os outros, com a comunidade, com a sociedade. Nos meios acadêmicos, nas avaliações, as publicações contam muito. $\mathrm{O}$ fato de propiciar aos outros essa oportunidade é respeitado, mas menos valorizado. Para usar uma outra imagem, o editor carrega o piano, mas quem é reconhecido é quem toca o mesmo. Uma das características do Sergio foi arregaçar as mangas e levantar o piano. Outra característica foi a paciência e o respeito prestados ao outro. A capacidade de ter paciência e pensar em prazos longos ficou evidente na construção e no passo a passo da revista. Nesse processo, ele sabia compartilhar as responsabilidades e respeitar os tempos e as disponibilidades dos parceiros.

E ainda, uma característica do Sergio que também merece destaque é o compromisso e a seriedade com que ele realizou seus trabalhos, que levou ele a não tolerar superficialidade, chavões e discursos fáceis, seja em textos ou trabalhos a avaliar, seja em projetos ou propostas. As críticas proferidas nestes momentos, porém, eram sempre bem fundamentadas e visavam a melhora, o desenvolvimento, o crescimento.

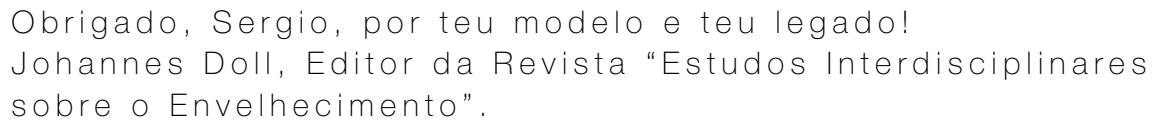

Conheci Sergio Antonio Carlos em 2001. Eu me apresentei para ser seu bolsista de pesquisa no projeto Trabalho e Aposentadoria. Na época, eu estudava Administração e Psicologia e não sabia muito bem como conciliar os dois cursos. Escolhi o grupo de pesquisa do Sergio para encontrar uma solução para uma busca pessoal e existencial. 
Sob a orientação de Sergio, comecei a entrevistar aposentados e aposentadas. Pessoas que dispunham de longas vidas de trabalho em seus percursos de vida. Era uma novidade para mim, que havia vivido a perda de meu irmão mais velho e de meu pai, e que buscava sentido para a vida. Meu pai e meu irmão viveram poucos anos, ao contrário dessas pessoas. As histórias de vida que me narravam eram o alento que eu buscava para seguir em frente.

Um dia, Sergio me disse que havia sentido um calafrio quando viu meu sobrenome inscrito para a seleção como bolsista. Mais tarde, ele confirmou que eu era neto de Cristiano Graeff Jr., a pessoa que havia intercedido em seu favor na obtenção de um primeiro emprego, na cidade de Cachoeira do Sul/ RS. A relação que tivemos à época passa tanto por esse encontro na vida de Sergio (Acaso? Destino?), quanto pelas perdas de meu pai e meu irmão.

Meu avô, Cristiano, faleceu na mesma época em que eu era orientado por Sergio. Eu escrevi um texto sobre essa perda, que Sergio leu com atenção e exigência, como fazia minha mãe. Sergio criticou o texto, talvez porque eu estivesse racionalizando demasiadamente a perda. Mas, sobretudo porque, assim como minha mãe, ele pressentiu que as críticas me fariam crescer.

E assim foi.

Sergio tornou-se uma figura paterna para mim. Ele ocupou o vazio que se abrira com as mortes sucessivas de um irmão mais velho, de um pai e de um avô. Fez isso sem pretensões, mas com generosidade e exigência. E, sobretudo, indicou-me o caminho da velhice, com suas tragédias e dramas, tão próprias e tão distintas da juventude. Para mim, cuja juventude entrou em coma em 1993 e teve fim em 1996, as tragédias e dramas da velhice são a consistência da vida humana. É o que nos espera, se tivermos a chance de ir além da juventude e da vida adulta. Essa chance, que faltou ao meu pai e ao meu irmão, é a matéria da última ousadia que escolhi para a minha vida: participar do envelhecimento de homens e mulheres que desejam viver vidas plenas, em seus domicílios, apesar das perdas que a velhice pode - e costuma - lhes impor; homens e mulheres que tiveram a sorte de viver para além dos 65 ou 70 anos de idade, mas sobretudo a coragem de enfrentar a vida quando o passado pesa mais que o futuro, quando o corpo torna-se estrangeiro e quando a solidão deixa de ser uma escolha e se impõe, pouco a pouco, como o preço a pagar por uma vida longa.

Sergio, neste dia em que as palavras que escrevo não serão lidas por ti, celebro a tua memória e compartilho a dor da tua partida com tua família. Em particular com Paula Pinhal de Carlos, amiga que esteve conosco em Paris quando eu estreava como pai e que, mais tarde, tornou-se minha colega na Unilasalle. 
Meus sentimentos estão com vocês.

Obrigado por participarem da minha vida, acompanhando-me e levando-me onde me encontro, hoje.

Descanse em paz, meu amigo, mentor e formador.

Lucas Graeff. 